\title{
The Pollutant Spreading Model AUSTAL 2000 Is Not Validated
}

\author{
Rainer Schenk \\ Rosenberg 17, D-06198 WETTIN-Löbejün, Germany
}

Copyright $(2017$ by authors, all rights reserved. Authors agree that this article remains permanently open access under the terms of the Creative Commons Attribution License 4.0 International License

\begin{abstract}
With individual examples [1 to 4] Schenk has demonstrated for AUSTAL2000 that the II. Law of Thermodynamics and the mass conservation law are violated. In [5] Truckenmüller et. 13 alii one contradicts and explains that AUSTAL is verified and validated yet. However, it turns out that there is a trivial solution in the posted derivation of the reference solution. It will be noted that this solution is not usable and performs speculative deposition rates and thus hurts the balancing differential equation. The correct nontrivial solution, which is suitable for the description of deposition and sedimentation are given in this paper. Beyond the generality of the earlier objections raised against AUSTAL occupied by valid integral theorems. They are not restricted to individual cases. Homogeneity tests turn out to be useless trivial cases and are not suitable for validation. For identical tasks, different solutions are given and direct users astray. It is claimed to have taken into account sources at $200 \mathrm{~m}$ height, but the simulation results do not show the effect of high altitude sources. Criticizable terminology shows that the authors of AUSTAL have little busy with the basics of momentum, heat and mass transfer laws. In the context of other inconsistencies, the author concludes that the grounds given by Janicke \& Janicke tests to sedimentation and deposition uniformity and could not have taken place. The life story of AUSTAL 2000 begins in 1984 with a fatal error and via LASAT to AUSTAL. She has found in 2016 a temporary end with an unprecedented sleight of hand. Mathematics and mechanics are used as valid tools of an incorruptible evidence.
\end{abstract}

Keywords Air Pollution, Spread of Air Pollutants, Emissions, Particle Model, Deposition, Sedimentation, AUSTAL2000

\section{Introduction}

To assess and review of the primary literature AUSTAL stands for [7] Janicke L. et al., [8] Janicke, [9] Janicke L., [10] Janicke U. et al., [11] VDI RL [12] Heimann, [13] and R.
Röckle [14] Thielen H. et al. available. Other bases for modeling the propagation of air pollutants and for program developments are et.al. in [15] Axenfeld F. and [16] IB Janicke described. The relevant reports on the development and description of AUSTAL for [8 to 10] have been drawn little manageable. The reader must gather individually, the mathematical and physical foundations of all reports. About development, practical application, claim and prognosis of AUSTAL can be found in [17] L. Janicke. With AUSTAL as their integral part ([18] TA Luft) was set in 2002 in force in the Federal Republic of Germany, the new TA Luft.

The development of AUSTAL began after [17] already in the year 1981 as the public an approach for modeling the so-called. Inhomogeneous turbulence was introduced. 1983 just ran the preparations for the elaboration of the TA Luft. Your medium- and long-term development has been discussed already at this time. The developed concept extends into the future five to seven years. The development of a model for calculating the dust deposition has been described in [15] 1984. One combines with AUSTAL high claims. When testing one accept as a service for all other model developments, quality assurance. Dispersion calculations to be carried out harmonized from the outset. The program package includes a reference solution is provided, must be checked at the other programs and validate. The reference solutions concern, for example comparative calculations for sedimentation and deposition, so-called for. Homogeneity and turbulence, validation with 3D wind fields and recalculation of BERLJAND profiles for [19] Berljand. With these reference solutions and comparative calculations, which are required by [11] for other program developers, it combines a high Prätentation. However, it was proved in [2], for example, that all the comparative calculations for deposition and sedimentation are faulty. They contradict the II. main law and the law of conservation of mass. Homogeneity tests turn out to be useless trivial cases and are not suitable for validation of dispersion models. 3D wind fields to be confused with the rigid rotation of a planar solid. The claim could have been recalculated dimensional BERLJAND profiles cannot be occupied. The error deviations of is up to $100 \%$. In all cases, to have been 
achieved at the end of 10 days, the stationary solutions, what is true for a single instance of the specified comparative calculations for deposition and sedimentation and homogeneity?

Between the beginning of the development AUSTAL in 1981 and entry into force of the new Technical Instructions on Air Pollution Control (TA Luft) in 2002, 21 years have passed. According to [17], if you want to meet again, to think about how the TA Luft is to make air in the next 20 years prognostically. Including various developments has been made continuing to the present. A completed and located in the new development application relates AUSTAL in version 2.5 , odor dispersion, according to [20] Janicke. To validate this model development identical reference solutions to sedimentation and deposition and homogeneity are indicated, one of which was established already in the described cases that they are not suitable for all erroneous and comparative calculations. Also on the proven faulty stationary simulation times of 10 days and on the BERLJAND profiles allegedly used is referenced. Neither subjected to the trouble to describe the physical peculiarities of the odor propagation, nor will this given appropriate reference solutions. Physically based different model approaches are ignored and little described. Only in [15] a rather adventurous conceptual model is described, for example to describe the deposition what the erroneous reference solutions declares. Further developments relate, for example, an online system for a nuclear power plant remote monitoring system, a software system for simulation and inhalation of radionuclides (LASAIR) and Airport induced to estimate emissions (LASPORT). Whether one uses the same incorrect reference solutions in the case of LASAIR and LASPORT, is not known. In addition, new developments for the calculation of concentration fluctuations by kinematic simulation of atmospheric turbulence and modeling of wet deposition reversibly dissolved gases are available. However, apparently only know the authors of AUSTAL what is to be understood.

In [5] one tries to refute the objections [ 1 to 4$]$ levied in and refer to various VDI guidelines and regulations. Textbook knowledge is not used. Simultaneously, the derivation of questionable reference solution will be published. In this paper it is demonstrated that this is wrong. The correct solution is given. By means of valid integral theorems is proved that the objections raised in [2] are universal and applicable not only to the described individual examples. In [6] Trukenmüller you deal with the objections raised, however, cannot detect the faulty implementation in [4]. For this reason, you want to at least demonstrate the equivalence, but one is unable to prove equivalence. The diversity is maintained and all contradictions are not invalidated. If the universality is demonstrated, it is not difficult to show further inconsistencies. These relate here all the case studies with "volume source over the entire computational domain", contradictory solutions in homonymous tasks and faulty solution curves in the case of high altitude sources. Criticizable terminology that the authors of the AUSTAL is required for modeling and calculation of the spread of air mixed in basic knowledge of the theory of momentum, heat and mass transfer inadequately available. In summary, the author comes to the conclusion that verification of AUSTAL could not have taken place.

The following considerations are based on the test case 11 for uniformity, the case 22a, sedimentation without deposition, and to the case $22 \mathrm{~b}$, with deposition sedimentation. All case studies refer to illustrations and descriptions for [8+ to 10]. As part of a root cause analysis the incorrect model assumptions of the authors of AUSTAL are described.

\section{Trivial Reference Solution after Janicke \& Janicke}

The authors of AUSTAL consider a one-dimensional stationary propagation process for validation. This is described by the differential equation (01) of Figure 1 and taken into account with the sedimentation rate $v_{s}$ a convective and with use of a $m_{i}=-K \cdot \partial c / \partial x_{i}$ conductive transport. It is an ordinary differential equation of second order, for their solution two boundary conditions are required. These are described by a constant concentration in the lowest layer $c_{0}$ and by the coincidence of conductive material and deposition power on the lower limit. Specification of a constant vertical material flow, which is mistakenly referred to by the authors of AUSTAL as area source, are obtained with the analytical solution, the concentration distribution, the concentration in the lowest layer and the associated sedimentation and deposition flows. $v_{s} \cdot c_{0}$ und $\mathrm{v}_{\mathrm{d}} \cdot c_{0}$ These analytical relationships are disregarded in the present case, as evidenced below.

As a solution of the equation (01) is [8 to 9] given by the relationship (02), which is according to Eq. (04) turns out to be a useless trivial solution. Equation (03) confirmed that the mass flow rate of the $\mathrm{z}$-coordinate is independent, so it can be used to calculate the concentration in the lowest layer. One distorts subsequently the solution by in which one speculative valid sedimentation stream swapped with the current deposition and subsequently unfounded, Eq. (05). The conductive material stream at the bottom and the deposition current mismatch is contrary to the validity of the II. Fundamental Theorem. Even the mass conservation law is violated. Den for true differential connection describes Eq. (05). The concentration distribution and the concentration in the lowest layer are calculated incorrectly too. 
$-v_{s} \cdot \frac{\partial c}{\partial z}=\frac{\partial}{\partial z}\left(K \cdot \frac{\partial c}{\partial z}\right) \quad F_{C}=K \frac{\partial c}{\partial z}+v_{s} \cdot c$

Homogeneous DE

$c(z)=c_{0} \cdot e^{-\frac{v_{S}}{K} \cdot z}+\frac{F_{C}}{v_{S}} \cdot\left(1-e^{-\frac{v_{S}}{K} \cdot z}\right)$

Inhomogeneous DE 1st order $F_{c}$ as a constant of integration

$$
\begin{aligned}
& -\frac{v_{s}}{K} \cdot z \quad c(z)=\text { const }=c_{i} \quad \text { Introduction of a } \\
& \text { also } F_{C}=v_{s} \cdot c_{i} \quad \begin{array}{ll}
\text { special solution } \\
\mathrm{F}_{\mathrm{c}}=v_{s}{ }^{*} \mathrm{C}_{1}
\end{array}
\end{aligned}
$$

Homogeneoussolution The integration constant $F_{c}$ is identical except for a proportionality factor of $\mathrm{c}_{\mathrm{i}}$

General solution Janicke \& Janicke the specific solution as $\mathrm{C}_{\mathrm{i}}$ Integration constants is unknown and has to be determined by valid boundary conditions.

$c_{i}=\frac{F_{C}}{v_{S}} \quad F_{C}=K \frac{\partial c}{\partial z}+v_{S} \cdot C=0+\frac{v_{S}}{v_{S}} \cdot F_{C} \quad F_{C}-F_{C} \equiv 0$

$$
F_{c}=v_{s} \cdot c_{j} \quad c(z)=\left(c_{0}-c_{j}\right) \cdot e^{-\frac{v_{s}}{k} \cdot z}+c_{i}
$$

The special solution $c_{i}$ satisfies the inhomogeneous differential equation of 1st order, however this is not known. You must be determined so that the mass conservation law is ensured as a boundary condition.

$Q=F_{C}=v_{s} \cdot c_{i}=v_{s} \cdot c_{0} \quad c_{i}=c_{0}$

Trivial solution Janicke \& Janicke with the yet unknown function $\mathrm{c}_{\mathrm{i}}$

$Q(z)=K \cdot \frac{\partial c}{\partial z} \cdot(z)+v_{s} \cdot c(z)=-\left(c_{0}-c_{j}\right) \cdot v_{s} \cdot e^{\frac{v_{s}}{K} \cdot z}$

$+\left(c_{0}-c_{j}\right) \cdot v_{s} \cdot e^{-\frac{v_{s}}{K} \cdot z}+c_{j} \cdot v_{s}=c_{j} \cdot v_{s}=$ konst $F_{c}=Q$

The integration constant $F_{c}$ is identical to the mass flow rate and of $z$ independent.

$c(z)=\left(c_{0}-c_{i}\right) \cdot e^{-\frac{v_{s}}{K} \cdot z}+c_{i}=c_{0}$

For the sake of constant mass is the selected special solution ci identical to soil concentration $c_{0}$. The mass flow rate is for each control section constant.

With the selected specific solution you get the meaningless trivial solution of a constant concentration distribution $c_{0}$, with missing model parameters.

$F_{C}=v_{d} \cdot c_{0} \quad c_{0}=\frac{F_{C}}{v_{d}}$

$F_{C}=K \cdot \frac{\partial c}{\partial z}+v_{s} \cdot C=0+\frac{v_{s}}{v_{d}} \cdot F_{C} \quad \mathrm{~F}_{\mathrm{c}}-\frac{v_{s}}{v_{d}} \cdot F_{C} \neq 0$

GI. (05)

Thus ever a disposition parameter appears in the solution, you replace the sedimentation flow by the deposition flow afterwards thus you violated the constant mass differentially, Eq. (05).

$c(z)=c_{0} \cdot e^{-\frac{v_{s}}{K} \cdot z}+\frac{F_{C}}{v_{S}} \cdot\left(1-e^{-\frac{v_{s}}{K} \cdot z}\right) \quad c(z)=c_{0} \cdot e^{-\frac{v_{s}}{K} \cdot z}+\frac{v_{d} \cdot c_{0}}{v_{S}} \cdot\left(1-e^{-\frac{v_{s}}{K} \cdot z}\right)$

Incorrect reference solution for validation of dispersion models by Janicke \& Janicke; it violates the law of conservation of mass. With this solution received deposition flows we would contradict the second law of thermodynamics. Consultants validate for over a decade at this faulty solution their propagation models.

Figure 1. Incorrect reference solution according Janicke \& Janicke

\section{Nontrivial Reference Solution by Schenk}

For the in section 2 explained the task, the formula sets the correct derivations of the reference solution are described in figure 2 .

The equations (07) are identical to the relations (01), and the solution method with the two integration constants A and $\mathrm{D}$ will be commented on by the equations (08). The determination of the constants of integration and derivation of the relevant non-trivial solution describe the relationships (09). With this solution, the concentrations in the lowest layer and deposition sedimentation streams and the distribution of air admixture can be calculated consistent when specifying a constant mass flow rate, $Q=c_{0} \cdot\left(v_{s}+v_{d}\right)$. The boundary conditions used and the deposition rate and the applicable material transitions are described by the equations (10) to (11). The II. main law and the mass conservation law are met. 
$-v_{s} \cdot \frac{\partial c}{\partial z}=\frac{\partial}{\partial z}\left(K \cdot \frac{\partial c}{\partial z}\right)$

Homogeneous DE 2nd order
$c=-\frac{K}{v_{s}} \cdot \frac{\partial c}{\partial z}+A$

Inhomogeneous DE

1st order
$c_{h}=-\frac{K}{v_{s}} \cdot \frac{\partial c_{h}}{\partial z}$

Homogeneous DE 1st order
$c_{h}=B \cdot e^{-\frac{V_{s}}{K} \cdot z}$

GI. (07)

Homogeneous solution

Theorem: "With In the integration of ordinary differential equationsof second order you get two constants of integration, which are to be determined by physically reasonable boundary conditions. "In addition to the trivial solutions we get not trivial solutions. The trivial solutions are in most cases not of interest. Of interest, however, are the non-trivial solutions.

This can inter alia be determined by the method of variation of constants.

$c=B(z) \cdot e^{-\frac{v_{s}}{K} \cdot z}$

$\frac{\partial c}{\partial z}=\frac{\partial B(z)}{\partial z} \cdot e^{-\frac{v_{s}}{K} \cdot z}-\frac{v_{S}}{K} \cdot B(z) \cdot e^{-\frac{v_{S}}{K} \cdot z}$

$B(z) \cdot e^{-\frac{v_{S}}{K} z}+\frac{K}{v_{S}} \cdot\left[B^{\prime}(z) \cdot e^{-\frac{v_{S}}{K} \cdot z}-\frac{v_{S}}{K} \cdot B(z) \cdot e^{-\frac{v_{S}}{K} \cdot z}\right]=A$

$\frac{\partial B(z)}{\partial z}=\frac{A \cdot v_{s}}{K} \cdot e^{\frac{v_{S}}{K} \cdot z} \quad B(z)=\frac{A \cdot v_{S}}{K} \int e^{\frac{v_{s}}{K} \cdot z} d z=A \cdot e^{\frac{v_{S}}{K} \cdot z}+D$

Theorem: "Lagrange has indicated a method to solve linear differential equations which can be applied as well for higher order." This solution method is known as "variation of constants "or "Lagrang'sches method". The general solution is a function of Integration constants $\mathrm{A}$ and $\mathrm{D}$, which are to be determined boundary conditions.
$c(0)=c_{0} \quad K \cdot\left(\frac{\partial c}{\partial z}\right)_{0}-v_{d} c_{0}=0$
$c_{0}=A+D \quad 0=v_{d} \cdot c_{0}+v_{s} \cdot D$
$A=c_{0} \cdot\left(\frac{v_{s}+v_{d}}{v_{s}}\right)$
$D=-c_{0} \cdot \frac{v_{d}}{v_{s}}$
$c(z)=c_{0} \cdot \frac{v_{s}+v_{d}}{v_{s}} \cdot\left(1-\frac{v_{d}}{v_{s}+v_{d}} \cdot e^{-\frac{v_{s}}{K} \cdot z}\right)$
$m_{K D}^{U}=-K \cdot\left(\frac{\partial c}{\partial z}\right)_{0}=-v_{d} \cdot c_{0}$
$c_{0}=\frac{Q}{\left(v_{S}+v_{d}\right)}$

The nontrivial solution describes the sedimentation and deposition as a function of the deposition and sedimentation rate, of the diffusion coefficients and of the source term $Q$. With a predetermined source one calculates the concentration in the first layer. The analytic relationship allows to calculate the concentration trend. In case of missing deposition we get in the lowest layer a vanishing concentration gradient.
$\Phi_{i}=v_{d} \cdot c_{j}$
$m_{K D}^{U}=v_{d} \cdot c_{0}$
$K_{z} \cdot \frac{d q}{d z}-\beta_{1} \cdot q=0$ für $z=0$
$K \cdot \frac{\partial c}{\partial z}-v_{d} \cdot c_{0}=0$ fur $z=0$
GI. (10)
GRAEDEL/CRUTZEN,(09), p.144,GI.(7.51) SCHENK
BERLJAND, (07), p.25, GI.(1.8)
SCHENK
$m_{K D}^{U}=(K)_{A} \cdot\left(\frac{\partial c}{\partial z}(0)\right)_{A}=\frac{(K)_{B}}{T} \cdot\left(c_{0}-c_{T}\right) \approx v_{d} \cdot c_{0} \quad v_{d}=\frac{(K)_{B}}{T}\left[\frac{m}{s}\right]$
Linear concentration profile in the soil
Deposition rate
$(K)_{A} \cdot\left(\frac{\partial c}{\partial z}(0)\right)_{A}=(K)_{B} \cdot\left(\frac{\partial c}{\partial z}(0)\right)_{B}$
Gl. (11)

Figure 2. Non-trivial reference solution by Schenk

\section{Application of Integral Theorems and Generality}

An individual examples was demonstrated for the case studies and sedimentation deposition that the II. main law and the mass conservation law are not met in [2].Means true integral equations can be proved that the formulated objections are universal. In Figure 3, all relevant formula sets are explained. The equations (12) are in turn identical to the original differential equation (01). After formation of volume integrals of Gaussian integral theorem is used to convert them into areas under the curve, with which subsequently at the boundaries the required scalar products can be formed, Eq. (13), Eq. (14). The balancing equation (15) is relatively applied subsequently to the solutions according Janicke \& Janicke and Schenk. The inequalities (16) and (17) occupy, in the case Janicke \& Janicke that they are opposed to Schenk, Eq. (19) and Eq. (20) is not met. After the inequality (16) of II. main law and after inequality (17) is violated the law of conservation of mass. 
Integral Equations

$-v_{S} \cdot \frac{\partial c}{\partial z}=\frac{\partial}{\partial z}\left(X \cdot \frac{\partial c}{\partial z}\right)$

$$
v_{i} \cdot \frac{\partial c}{\partial x_{i}}=\frac{\partial}{\partial x_{i}}\left(K \cdot \frac{\partial c}{\partial x_{i}}\right)
$$

Homogenous differential equation, sedimentation and deposition without source term according AUSTAL

$\int V_{i} \cdot \frac{\partial c}{\partial x_{i}} d V=\int \frac{\partial}{\partial x_{i}}\left(K \cdot \frac{\partial c}{\partial x_{i}}\right) d V=\oint c \cdot V_{i} d A_{i}=\oint K \cdot \frac{\partial c}{\partial x_{i}} d A_{i} \quad \oint c \cdot V_{i} d A_{i}-\oint K \cdot \frac{\partial c}{\partial x_{i}} d A_{i}=0$

Volume integrals and applying Green's theorem, GAUSS'scher Integralsatz

$$
\left(c \cdot v_{i}\right)_{K V}^{O} \cdot\left(A_{j}\right)^{O}+\underbrace{\left(c \cdot v_{i} M_{k V}^{M} \cdot\left(A_{i}\right)^{M}\right.}_{=0}+\left(c \cdot v_{i}\right)_{K V}^{U} \cdot\left(A_{i}\right)^{U}+\left(m_{i}\right)_{K D}^{O}\left(A_{i}\right)^{O}+\underbrace{\left(m_{i}\right)_{K D}^{M}\left(A_{i}\right)^{M}}_{=0}+\left(m_{i}\right)_{K D}^{U}\left(A_{i}\right)^{U}=\sum_{i=1}^{i-4} m_{i}=0
$$

Formation of scalar products at the boundaries of the lowest layer

$\sum_{i=1}^{i-4} m_{i}=m_{K V}^{O}+m_{K V}^{U} \cdot+m_{K D}^{O} \cdot+m_{K D}^{U}=0$

$m_{K V}^{O}=-c(h) \cdot v_{S}(h) \quad m_{K V}^{U}=c(0) \cdot v_{s}(0) \quad m_{K D}^{O}=-K \cdot \frac{\partial c}{\partial z}(h) \quad m_{K D}^{U}=c(0) \cdot v_{d}$

Balance equation

Convective and conductive material flows at the range limits

\section{Sedimentation and deposition, incorrect solution according Janicke \& Janicke}

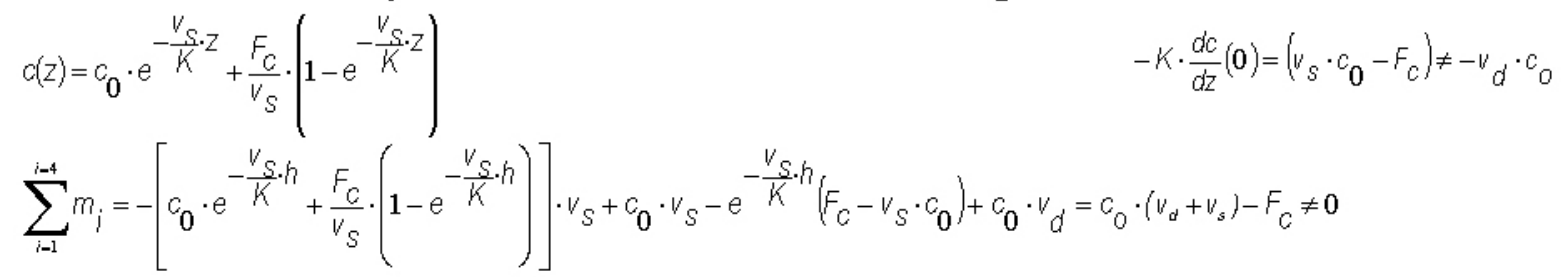

The II. Law of thermodynamics, according to Eq. (16) and the mass conservation law according to Eq. (17) are violated.

\section{Sedimentation and deposition, nontrivial solution by Schenk}

$\begin{array}{lll}c(z)=c_{0} \cdot \frac{v_{s}+v_{d}}{v_{s}} \cdot\left(1-\frac{v_{d}}{v_{s}+v_{d}} \cdot e^{-\frac{v_{s}}{K} \cdot z}\right) c_{0}=\frac{Q}{\left(v_{s}+v_{d}\right)} & \text { Gl. (18) } & -K \cdot \frac{d c}{d z}(0)=-v_{d} \cdot c_{0} \\ \sum_{i=1}^{i-4} m_{i}=-c_{0} \cdot \frac{v_{s}+v_{d}}{v_{s}} \cdot\left(1-\frac{v_{d}}{v_{s}+v_{d}} \cdot e^{-\frac{v_{s}}{K} \cdot h}\right) \cdot v_{s}+c_{0} \cdot v_{s}-c_{0} \cdot v_{d} \cdot e^{-\frac{v_{s}}{K} \cdot h}+c_{0} \cdot v_{d} \equiv 0 & \end{array}$

The II. Law of thermodynamics, according to Eq. (19) and the mass conservation law according to Eq. (20) are satisfied.

Figure 3. Application of integral theorems on the incorrect solution after Janicke \& Janicke and nontrivial solution by Schenk

\section{Comparative Calculations Homogeneity and Sedimentation and Deposition with "Volume Source over the Entire Computational Domain" Are Useless Trivial Cases with Just Such Solutions}

The following considerations of Figure 4 apply to all test cases to homogeneity and on the case example 22a, sedimentation without deposition, in the case of homogeneity here by way of example, the case is considered 11. All these cases have in common that it is considered in the test calculations of the authors of AUSTAL from a "source volume over the entire computational domain". In all other cases, you look curiously enough, notwithstanding, sources, which should have been situated at $200 \mathrm{~m}$ height.
While described for all homogeneity tests of the diffusion compensation by the equation (21), it is in the case $22 \mathrm{a}$ with a freely selectable sedimentation the differential equation (25). In the case of homogeneity tests one would like to hold the diffusion coefficient constant or optional spatially variable, which indicate the authors of AUSTAL erroneously as a homogeneous or inhomogeneous turbulence, although it is merely a simple diffusion process with a lack of convection. But the presence of turbulence sets convective motions ahead, but in the case of homogeneity tests cannot be guaranteed and also the requirement contradicts. Even here the contradictory terms of tasks and the strangely chosen concepts lead to considerable confusion. In the case of 11 one would like to investigate the effect of different so-called turbulence approaches and with the case study $22 \mathrm{a}$ the impact of sedimentation on the propagation process. However, the authors fail to recognize here is that in all cases 
volume source over the entire computational domain have spatial concentration gradients disappear after equation (22). After that prepare their financial statements the equations (21) and (22) because of the reduced product formation between lack of gradient and a factor somehow a common trivial differential equation with a similar solution, Eq. (24).

The original intention to investigate the influence of homogeneous and inhomogeneous turbulence with these tasks, fails because all solutions of arbitrarily chosen diffusion approaches are independent. For the case study 22a the same observation is true, since the sedimentation rate as in the previous case, the diffusion equation can have no influence on the solution of the propagation process because of the vanishing concentration here. Not only just so is well founded, that a validation of AUSTAL could not have taken place. All model parameters are, inter alia, described in [8], which the source term to $0,139 \mu \mathrm{g} /\left(\mathrm{m}^{3 *} \mathrm{~s}\right)$ can be calculated from Eq. (23). That should be so directed consciously astray because of the words "Source volume over the entire computational domain" and erroneous reference solutions of reading, is not alleged.

\section{Case 11, homogeneity test "on the source volume entire computational domain ", numeri- cal simulation}

$\frac{\partial c}{\partial t}=\frac{\partial}{\partial x}\left(X \cdot \frac{\partial c}{\partial x}\right)+\frac{\partial}{\partial y}\left(X \cdot \frac{\partial c}{\partial y}\right)+\frac{\partial}{\partial z}\left(X \cdot \frac{\partial c}{\partial z}\right)+q$

$\left\{\frac{\partial c}{\partial n}\right\}_{R}=0$

Unsteady diffusion

$\dot{q}=\frac{E}{V \cdot \Delta t}=\frac{100 \mathrm{~kg}}{2 \cdot 10^{08} m^{3} * 3600 s}=0,139 \frac{\mu g}{m^{3} \cdot s}$

The emission occurs only in the first hour of the first day.
Gl. (21)

$$
\left\|c_{1}\right\| \leq\|T\| \cdot\left\|c_{0}\right\|+\tau \cdot\|\dot{q}\| \quad\|c(t)\| \leq\left\|T_{i}\right\| \cdot\|c(t=0)\|+\|\cdot\| \cdot \| \cdot \sum_{i=0}^{n} \tau_{i}
$$$$
\mathrm{t}=\sum_{i=0}^{n} \tau_{i} \lim _{\mathrm{i} \rightarrow \infty}\left\|T_{i}\right\|=0 \quad\|T\| \leq 1 \quad \mathrm{c}(\mathrm{t}=0)=0 \quad \dot{\mathrm{q}}=\text { konst } \Rightarrow \frac{\partial \mathrm{c}(\mathrm{t})}{\partial x_{i}} \equiv 0
$$

Functional analytic description, constant source

GI. (23)

$\frac{\partial c}{\partial x}=\frac{\partial c}{\partial y}=\frac{\partial c}{\partial z}=0 \quad \frac{\partial c}{\partial t}=\dot{q} \quad \mathrm{c}=\dot{\mathrm{q}} \cdot \mathrm{t} \quad \mathrm{c}=\dot{q} \cdot \Delta t=0,139 \cdot 3600=500 \frac{\mu g}{m^{3}}$

About the whole Trivial differential equation and just such a soterritory 


\section{For One and the Same Task Are Two Different Solutions Indicated}

In Section 5 has been shown that reducing the tasks of the cases 11 and 22 on one and the same differential equation (24). After that is independent of all diffusion approaches and sedimentation after $3600 \mathrm{~s}$ the concentration of $500 \mu \mathrm{g} / \mathrm{m}^{3}$ achieved and not after10 days, as indicated by the authors of AUSTAL. At least, after the A graphic Figure 5 and according to [8], p 52, and [9], p 28, the steady state concentration of $500 \mu \mathrm{g} / \mathrm{m}^{3}$ specified correctly. In case $22 \mathrm{a}$ with the same resolution of the case 11 on the other hand, after graphics B after [8], p 56, and [9], p.33, Figure 7, one of the case of 11 different faulty exponential indicated.
It is now before the event that one specifies for one and the same tasks, two different solutions, which must irritate the reader. How so dispersion models to be validated, cannot be explained.

Further studies by [21] Schenk lead to the conclusion that the concentration distribution by graphic B is already defective, and the concentration in the lowest layer has been determined with $1100,6 \mu \mathrm{g} / \mathrm{m}^{3}$ speculative. Furthermore, the presence of air mixed in is basically to question, since the case $22 \mathrm{a}$ by [8], p.56, with the premise of no air admixtures are emitted, $F_{c}=0$. Also this example shows that a validation of AUSTAL so could not have taken place.

\section{For one and the same task there are stated two different solutions}

Solution history for case 11 of the homogeneity tests according Janicke \& Janicke
Solution history for case 22 a of sedimentation and deposition tests by Janicke \& Janicke

$$
\frac{\partial c}{\partial t}=\dot{q} \quad \mathrm{c}=\dot{\mathrm{q}} \cdot \mathrm{t} \quad \mathrm{c}=\dot{q} \cdot \Delta t=0,139 \cdot 3600=500 \frac{\mu g}{m^{3}} \quad \text { GI. (24) }
$$

Identical task and trivial differential equation just such a solution for the cases 11 and $22 \mathrm{a}$

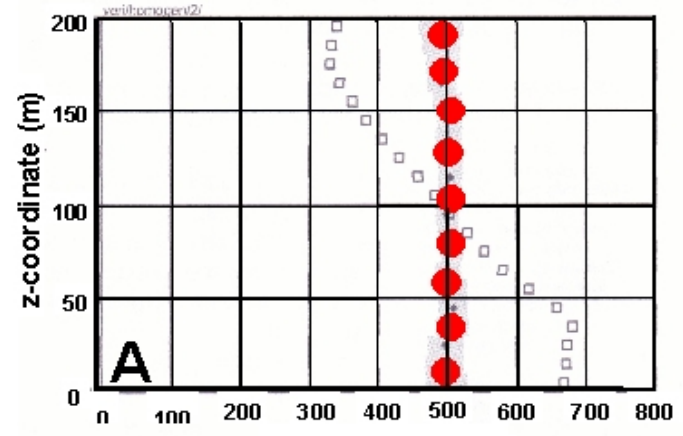

Concentration $\mathrm{ME} / \mathrm{m}^{3}\left(\mu \mathrm{g} / \mathrm{m}^{3}\right)$

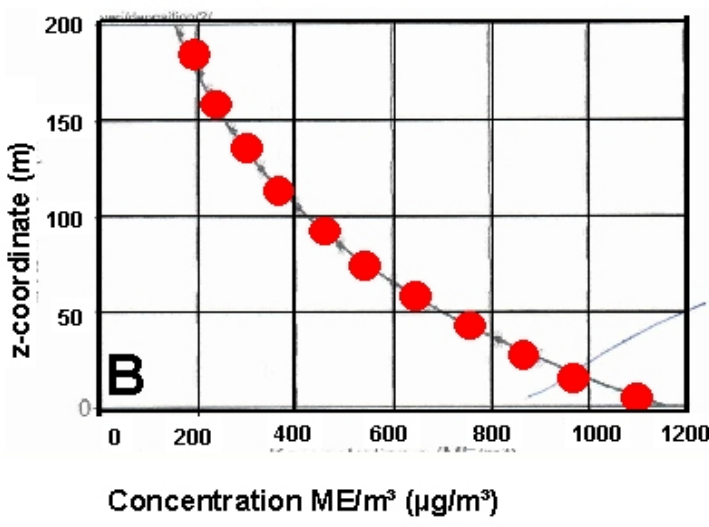

Concentration $\mathrm{ME} / \mathrm{m}^{3}\left(\mu \mathrm{g} / \mathrm{m}^{3}\right)$

Comparing the simulation results to the case 11 and the case $22 \mathrm{a}$ one recognizes that by specifying 'volume source over the entire computational domain "for both cases identical tasks we get trivial Differential equation, and just such a solution, Eq. (23) and Eq. (24). In an identical task Janicke \& Janicke get preposterous two different solutions, image A and image $\mathrm{B}$. In the first case, one describes a constant concentration profile with $500 \mu \mathrm{g} / \mathrm{m}^{3}$ in the second case, a wrongly barometric distribution. The concentration distribution of the image $B$ is calculated speculatively. One has although a differential equation but no conceptual model. Program developers have to prove their algorithms (software) for one and the same task with two different solutionst. How this should be done, cannot be traced. It is doubtful that comparative calculations to AUSTAL and verifications ever have taken place.

Figure 5. Identical tasks and different solution curves 
Case 22b, deposition with sedimentation according AUSTAL, source is allegedly located at $200 \mathrm{~m}$ altitude

Faulty solution development in the given computational domain with sources

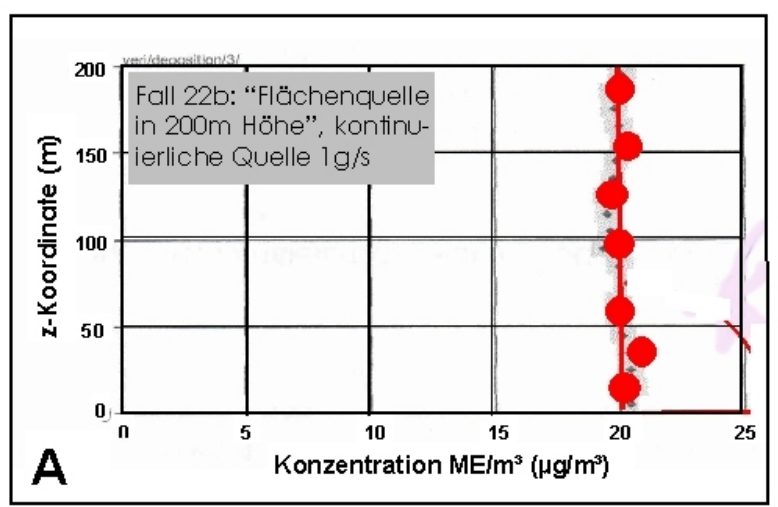

Parameter, incorrect solution and advanced computational domain with questionable source height

Computational domain, meteorology, source

$d x=d z=1000 \mathrm{~m}, d y=10 m v_{s}=v_{d}=0.05 \mathrm{~m} / \mathrm{s}$, $\mathrm{K}=1 \mathrm{~m}^{2} / \mathrm{s}$, questionable source height hq $=$ $200 \mathrm{~m}, \mathrm{~F}_{\mathrm{c}}=1$.mu.g $/\left(\mathrm{m}^{2}{ }^{*} \mathrm{~s}\right)$, questioablen time series of 10 days

Faulty solution and soil concentration by Janicke \& Janicke

$c(z)=c_{0} \cdot e^{-\frac{v_{s}}{K} \cdot z}+\frac{F_{C}}{v_{s}} \cdot\left(1-e^{-\frac{v_{s}}{K} \cdot z}\right)$

GI. (06)

$F_{C}=c_{0} \cdot v_{d} \quad \mathrm{c}_{0}=20 \mu \mathrm{g} / \mathrm{m}^{3} \quad \mathrm{~F}_{\mathrm{c}}=1 \mathrm{~m}^{2} / \mathrm{s}$

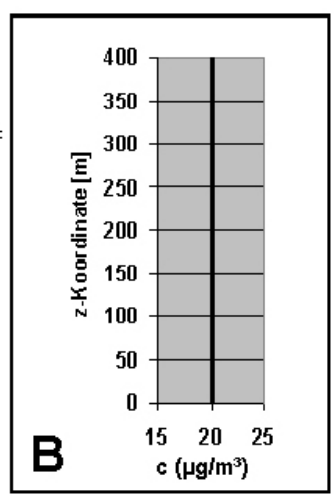

In the reference example $\mathrm{A}$, the concentrations in the lowest layer are calculated to $20 \mathrm{ug} / \mathrm{m}^{3}$ with incorrect concentration Curves. The deviation is $100 \%$. The conductive material stream in the lowest layer is not identical with the deposition stream. Thereby, the mass conservation law and of II: Law of thermodynamics are injured. The effect of a source at $200 \mathrm{~m}$ cannot be seen. The stationary final states are after 10 days should have been reached, however, the compensation has already been reached after $2.6 \mathrm{~h}$.

Case 22b, deposition with sedimentation according Schenk, analytical and numerical studies for highaltitude sources

Numerical experiments on the effect of different Source heights according correct solution

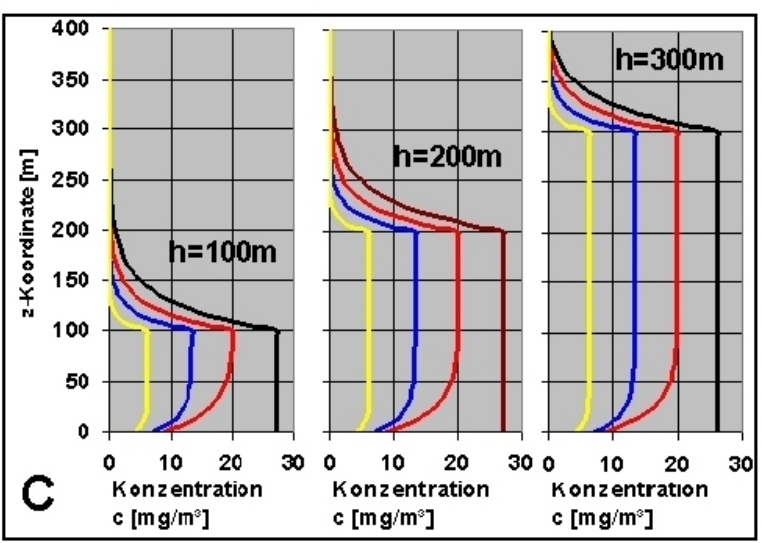

\section{Reference Example A to D image and the correct solution source $200 \mathrm{~m}$}

With deposition

$\begin{array}{cc}\mathrm{Vd}=0,05 \mathrm{~m} / \mathrm{s} V \mathrm{vs}=0,050 \mathrm{~m} / \mathrm{s} & \mathrm{Vd}=0,05 \mathrm{~m} / \mathrm{s} \mathrm{Vs}=0,160 \mathrm{~m} / \mathrm{s} \\ \text { Tstat }=2,6 \mathrm{~h} & \text { Tstat }=0,3 \mathrm{~h}\end{array}$

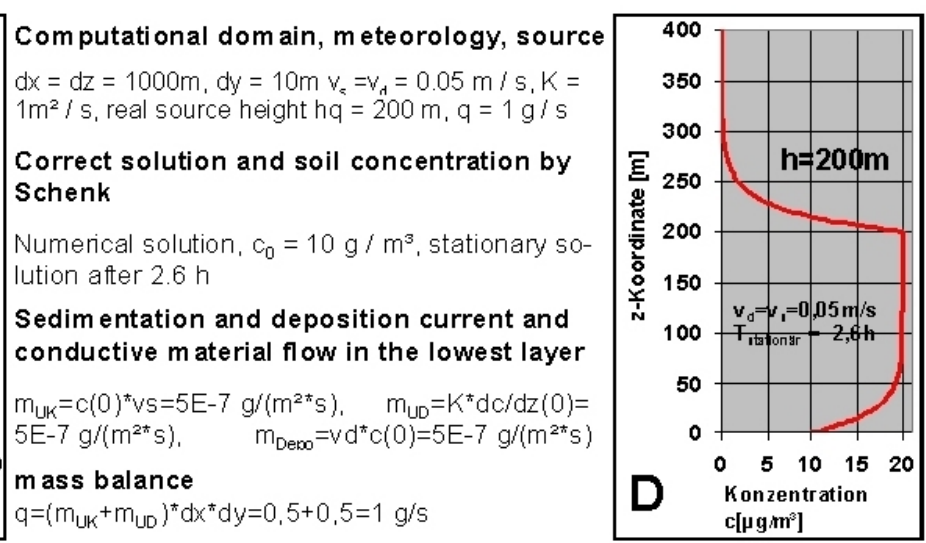

Without deposition

$$
\text { - } \underset{T}{\mathrm{Tstat}=1,3 \mathrm{~h}} \mathrm{~d}=0,05 \mathrm{~m} / \mathrm{s} \text { vs=0,075m/s }
$$

- $v d=0,00 \mathrm{~m} / \mathrm{s} V \mathrm{~s}=0,037 \mathrm{~m} / \mathrm{s}$ Tstat=4,6h

The proper concentration in the lowest layer is $10 \mu \mathrm{g} / \mathrm{m}^{3}$. The conductive material flow in the lowest layer is identical to the deposition stream. The mass conservation law and of II. law of thermodynamics are fulfilled. The concentrations trends reflect the real behavior. The effect of high altitude sources can be clearly seen. With the concentrations in the lowest layer we can determine sedimentations- and deposition flows error-free in accordance with the main and conservation laws. The total emission is $1 \mathrm{~g} / \mathrm{s}$. The stationary final states are different. In the case of the reference example is the stationary final state after $2.6 \mathrm{~h}$ reached and not after 10 days.

Figure 6. Sources are allegedly located in $200 \mathrm{~m}$

\section{Supposedly Sources Have Lain at $200 \mathrm{~m}$}

Unlike the case of example 22a, was in which, as with all homogeneity tests of an assumed "volume source over the entire computational domain", taking into account for [8 to 9] for example calculations 21 and $22 \mathrm{~b}$ by derogation and unfounded area sources at $200 \mathrm{~m}$, but let the purpose calculated concentration distributions do not recognize the effects of high altitude sources.

Also there is no way to determine the source heights in this specified analytical solutions or vary such as can be seen in the incorrect solution (06) for the reference case $22 \mathrm{~b}$. Between the formulated tasks and the reported results are contradictions cannot be overlooked.

From the author of these discrepancies were taken as an 
opportunity to recalculate the amounts reported by the authors of AUSTAL simulation results considering varied source heights numerically. Comparatively, these results are described in figure 6 . The graph A shows the concentration distribution for the case $22 \mathrm{~b}$ of the authors of the AUSTAL. The upper limit of the control room is limited vertically with $200 \mathrm{~m}$. The graph describes the specified propagation parameters and the erroneous reference solution (06) a constant concentration of $20 \mu \mathrm{g} / \mathrm{m}^{3}$ distribution, which at the upper boundary at $200 \mathrm{~m}$ a source should have been lying. In the graph $\mathrm{B}$ a similar constant concentration distribution is shown by equation (06), however, the control room has been extended up to $400 \mathrm{~m}$ in order to represent the effect of possible sources. The presence of a source at $200 \mathrm{~m}$ is not apparent. Using identical model parameters the bill was repeated, taking into account varied source heights by means of a numerical method. The result shows the graph $\mathrm{C}$ where the studied source heights are $100 \mathrm{~m}, 200 \mathrm{~m}$ and $300 \mathrm{~m}$ amount.

At constant deposition velocity $v_{d}$ against the sedimentation rates $v_{s}$ are different in the specified interval. The soil concentration for the Reference Case $200 \mathrm{~m}$ not is $20 \mu \mathrm{g} / \mathrm{m}^{3}$ but only $10 \mu \mathrm{g} / \mathrm{m}^{3}$, which can be recalculated with the correct reference solution (09) and for a constant mass flow rate of the $Q=c_{0} \cdot\left(v_{s}+v_{d}\right)=1 \mu g /\left(m^{2} * s\right) \mathrm{rd}$. The error thus amounts to $100 \%$. The influence of different source heights on the concentration distribution is unlike AUSTAL clearly. In addition, it is observed that in the case of a vanishing deposition rate for $v_{d}=0 \mathrm{~m} / \mathrm{s}$ of the deposition current disappears. The concentration gradient and hence the conductive material stream at the bottom are also equal to zero, which is in agreement with equation (19). The II. main law and the mass conservation law are met. By contrast, A is the case AUSTAL despite a vanishing concentration by graphics asserts a deposition power can occur. They disregarded that after the II. Law of conductive material flow must coincide with the deposition stream at the bottom. In addition, it can be recalculated, that the mass conservation law is violated. The graph D shows again $200 \mathrm{~m}$ conditions for the reference case. During indicated by the authors of AUSTAL outlandish for all tests for deposition and sedimentation and homogeneity that all equalization times should have amounted to 10 days is this only $2.6 \mathrm{H}$ in the present case. In Figure 6 the complete information on computational domain and meteorology as well as the determined sedimentation and deposition currents are given for the reference case. The validity of the mass balance is evidenced by a recalculation.

In conclusion, there is the result that the purpose of the authors of AUSTAL assertion, one would have considered sources at $200 \mathrm{~m}$, is not true. The base concentration is calculated incorrectly. It specifies a deposition power would take place, though this cannot occur because of the vanishing concentration gradient at the bottom. The recovery time is calculated incorrectly. Also this information is not true, as can be recalculated. How would like to develop with such eccentricities dispersion models, cannot be explained. The authors of AUSTAL develop this strange model concept. Comparative calculations with a source altitude of $200 \mathrm{~m}$ have been held.

\section{Difference between the Reference Solutions}

The inequalities (05), (16) and (17) show that the reference solutions of AUSTAL violate the II. law of thermodynamics and the conservation of mass. In the essay [6], the authors of AUSTAL grapple with this formula set of figures 1,2 and 3 and cannot identify any error in the derivations. For this reason, we want to demonstrate an equivalence, bringing all inconsistencies have cleared up at least. However it is evident that this is a fallacious argument.

Regardless of the statements by [6] to the equivalence of reference solutions should first be pointed out that from the equivalence cannot be spoken. The required matching sets of formulas and the physical principles are described in the figure. 7 The Eq. (29) explains the correct reference solution $\mathrm{N}(\mathrm{z})$, while Eq. (30) the faulty AUSTAL solution M (z) explained. To demonstrate equivalence, both solutions are equivalent to the relations (31). With the following result $\exp (a) \neq 1$ is shown that in contrast to the embodiments according to [6] not equivalent and therefore no identity exists. Only in the case of assumptions, which preclude the formulated tasks and physically are preserved, such as a vanishing sedimentation $v_{s}=0$, an unrealistic diffusion coefficient $K \rightarrow \infty$ and limitation of the study area to only a single field point $z=0$ would be guaranteed equality. It has been previously demonstrated by [4] that it is in the equation (30) in consideration of valid boundary conditions to a trivial solution. 


\section{Equivalences are detected by identities}

$$
c(z)=N(z)=c_{0} \cdot\left(1+\frac{v_{d}}{X} \cdot z\right)
$$

Deposition ohne Sedimentation nach SCHENK

$c(z)=M(z)=F_{C} \cdot\left(\frac{1}{v_{d}}+\frac{z}{K}\right)$

Deposition without sedimentation after JANICKE

$N(z) \equiv M(z)$

$c_{0} \cdot\left(1+\frac{v_{d}}{K} \cdot z\right) \equiv F_{C} \cdot\left(\frac{1}{v_{d}}+\frac{z}{K}\right)$

$1+\frac{v_{d}}{K} \cdot z \equiv \frac{v_{d}}{v_{d}}+\frac{v_{d} \cdot z}{K}$

$v_{d} \equiv v_{d}$

Identity between Eq. (26) and Eq. (27)

GI. (27)

Gl. (28)

\section{Difference between the reference solutions of AUSTAL2000}

$c(z)=N(z)=c_{0} \cdot \frac{v_{s}+v_{d}}{v_{s}} \cdot\left(1-\frac{v_{d}}{v_{s}+v_{d}} \cdot e^{a}\right)$

GI. (29)

Deposition by sedimentation with SCHENK

$c(c)=M(z)=c_{0} \cdot e^{a}+\frac{F_{C}}{v_{S}} \cdot\left(1-e^{a}\right) \quad F_{C}=c_{0} \cdot v_{d} \neq c_{0} \cdot v_{s}$

GI. (30)

Faulty deposition with sedimentation after JANICKE

$N(z) \neq M(z)$

$c_{0} \cdot \frac{v_{S}+v_{d}}{v_{S}} \cdot\left(1-\frac{v_{d}}{v_{S}+v_{d}} \cdot e^{a}\right) \neq c_{0} \cdot e^{a}+\frac{F_{C}}{v_{S}} \cdot\left(1-e^{a}\right)$

$\frac{v_{s}+v_{d}}{v_{s}}-\frac{v_{d}}{v_{s}} \cdot e^{a} \neq e^{a}+\frac{v_{d}}{v_{s}}-\frac{v_{d}}{v_{s}} \cdot e^{a}$

GI. (31)

Difference between the reference solutions to Eq. (29) and GL (30)

$a=-\frac{v_{S}}{K} \cdot z \quad\left(v_{S} \neq 0\right)$ or $(z \neq 0)$ or $(K \neq \infty)$ Abbreviations and Scope

In order to demonstrate an equivalence the different reference solutions (29) and (30) must be equated. There is no identity between the two solutions. An equivalence, in contrast to the relations (28) can not be proved. While the equation (26) describes a propagation without sedimentation, the relationship (29) considers sedimendation and deposition equally.

Figure 7. An equivalence between the reference solutions for sedimentation and deposition can not be detected

The valid sedimentation $F_{c}=c_{0} \cdot v_{s}$ is also inadmissible replaced by the deposition $c_{0} \cdot v_{d}$ so that the deposition rate $v_{d}$ so found as free model parameters is at least considered in the reference solution. To demonstrate how equivalences can be demonstrated, the equations (26) and (27) are also equated in another case. The analytical relationship according to equation (28) occupies the existing equivalence here. The difference with respect to the derivation according to the equations (31) is evident.

It will enlighten be of interest, as opposed to the relations (31) the apparent equivalence is declared between the reference solutions in [6]. These considerations are of considerable importance in so far as the physically correct description of the deposition has a significant impact on the reliability of all dispersion modeling in general.

The relevant form sets Eq. (32) to Eq. (35) used in [6] for the proof of equivalence are shown in Fig 8. With the relation (33) $v_{d}^{\text {Schenk }}=v_{d}^{\text {Janicke }}-v_{s}$, one would like to prove a supposed equivalence, but the physical validity of this relation is not substantiated. It is also not clear why two deposition rates must be differentiated, $v_{d}^{\text {Schenk }}=v_{d}^{\text {Janicke }}-v_{s}$ and $v_{d}^{\text {Janicke }}$.

It will enlighten be of interest, as opposed to the relations (31) the apparent equivalence is declared between the reference solutions in [6]. These considerations are of considerable importance in so far as the physically correct description of the deposition has a significant impact on the reliability of all dispersion modeling in general.

One should know that the deposition rate is a material constant as an independent model parameter and, at best, could be dependent on the temperature, but not by the rate of sedimentation $v_{s}$ in the free atmosphere as another free parameter yet. Deposition rates can be found in different table works, such as according to Figure A of Figure 8. That sedimentation rates can be considered here is not to recognize. The relationship (33) is unfounded and is not described in the literature. Only in [6] that is used for the detection of alleged equivalences first and unfounded. As deposition rates are to be understood, the figure 8 can be also removed. You cannot be somehow defined. 
Dry deposition: equivalence of reference solutions by Schenk and Janicke

ALFRED TRUCKENMÜLLER, Ummeltbundesamt Dessau, 2016-03-04, Germany, S. 1-3

$c(z)=c_{0} \cdot \frac{v_{s}+v_{d}^{\text {Schenk }}}{v_{s}} \cdot\left(1-\frac{v_{d}^{\text {Schenk }}}{v_{s}+v_{d}^{\text {Schen } k}} \cdot e^{a}\right)$

"Presented by Schenk reference solution"

$F_{C}=c_{0} \cdot v_{d}^{\text {Janicke }} \neq c_{0} \cdot v_{s} \quad v_{d}^{\text {Schenk }}=v_{d}^{\text {Janicke }}-v_{s}$

"taking into account the relationship..."
GI. (32) $c(z)=c_{0} \cdot\left[\frac{v_{d}^{\text {Janicke }}}{v_{s}}+\left(1-\frac{v_{d}^{\text {Janicke }}}{v_{s}}\right) \cdot e^{a}\right]$

"...be written as " thus

GI. (33)

$$
c(z)=\frac{F_{C}}{v_{d}}+\left(c_{0}-\frac{F_{C}}{v_{s}}\right) \cdot e^{a}=c_{0} \cdot e^{a}+\frac{F_{C}}{v_{s}} \cdot\left(1-e^{a}\right)
$$

"..follows Janickes reference solution"

To bring about a supposed equivalence between the reference solutions, the arbitrary deposition velocity $v_{d}$ is considered as the dependent variable.

\section{The deposition velocity is a material constant and can not be defined differently}

$\Phi=(K)_{A} \cdot\left(\frac{\partial c}{\partial z}(0)\right)_{A}=\frac{(K)_{B}}{T} \cdot\left(c_{0}-c_{T}\right) \approx v_{d} \cdot c_{0} \quad v_{d}=\frac{(K)_{B}}{T}\left[\frac{m}{s}\right]$

Deposition power and deposition rate

$k \cdot \frac{\partial c}{\partial z}-v_{d} \cdot c_{0}=0$ für $z=0$

$(K)_{A} \cdot\left(\frac{\partial c}{\partial z}(0)\right)_{A}=(K)_{B} \cdot\left(\frac{\partial c}{\partial z}(0)\right)_{B}$

boundary condition

Mass transfer

\begin{tabular}{lr}
\hline Oberfläche & $v_{d}(\mathrm{~cm} / \mathrm{s})$ \\
\hline Mischwald & $1,8-3,7$ \\
Boden (kalkig) & $0,3-1,0$ \\
&
\end{tabular}

Figure $\mathrm{A}$, deposition rate as a material constant *)

The deposition rate is a material constant and, optionally, depending on the temperature. There is no evidence that they could be selected from tables in dependence of sedimentation rate.

\section{Analytical method for bringing about a supposed equivalence to TRUKENMÜLLER}

$M(z)=c_{0} \cdot\left[e^{a}+\frac{v_{d}}{v_{s}} \cdot\left(1-e^{a}\right)\right]$

Incorrect reference soIution $\mathrm{M}(\mathrm{z})$ according Janicke \& Janicke
GI. (36)

$N\left(z, v_{d}\right)=c_{0} \frac{v_{s}+v_{d}}{v_{s}} \cdot\left(1-\frac{v_{d}}{v_{s}+v_{d}} \cdot e^{a}\right)=N\left(z, v_{d}=x\right)=c_{0} \frac{v_{s}+x}{v_{s}} \cdot\left(1-\frac{x}{v_{s}+x} \cdot e^{a}\right)$

Correct reference solution $N\left(z, v_{d}\right)$, the deposition velocity $v_{d}$ as an independent parameter is replaced $v_{d}$ by TRUCK MÜLLER by a dependent parameter $v_{d}=x$ without valid reasons.

$M(z)=N(z, x) \quad e^{a}+\frac{v_{d}}{v_{S}} \cdot\left(1-e^{a}\right)=\frac{v_{S}+x}{v_{S}}-\frac{x}{v_{S}} \cdot e^{a} \quad x \cdot\left(e^{a}-1\right)=v_{d} \cdot\left(e^{a}-1\right)-v_{S} \cdot\left(e^{a}-1\right) \quad x=v_{d}-v_{S}$

TRUCKENMÜLLER viewed $M(z)=N(z, x)$ as the equation for $x$. After renaming $x=v d^{\text {Scherk }}$ and $v d=v d^{\text {Janicke }}$ the analytical result is designed as a definition for deposition rate $v d^{\text {scherk }}=v d^{\text {Janicke }}-v s$, so you can easily reflect a supposed equivalence. This apparent definition lacks any physical justification and other authors are said untruthfully.

*) Source: Urban climate and air pollution control, VDI KRdL, Springer Verlag 1988, p 253

Figure 8. difference between the reference solutions

It is still to be clarified, according to which method the relation (33) by [6] is determined. This will also emphasize why a distinction is made between two arbitrary deposition rates. One tries thus bringing about the apparent equivalence, by equating the correct reference solution $N(z)$ according to Eq. (37) with the incorrect solution to (36) $M\left(z, v_{d}\right)$ and at the same time $\mathrm{x}$ replaces the independent parameters $v_{d}$ by a dependent parameter $\mathrm{x}, M(z)=N(z, x)$. This is it determined as following by a supposed equality.

Thus, the relation (33) is calculated as traced by the example of the equations (38). From the equations (38) follows the equation (33) $v_{d}^{\text {Schenk }}=v_{d}^{\text {Janicke }}-v_{s}$ if one finally renaming again the variables, $x=v_{d}^{\text {Schenk }}$ and $v_{d}=v_{d}^{\text {Janicke }}$. By one would solve the conflicting task conversely get the equivalent relationship. It turns out that an equivalence is merely tricked in this way, $M(z, x)=N(z)$ and $v_{d}^{\text {Janicke }}=v_{d}^{\text {Schenk }}+v_{s}$. It is also understandable that you do not inadvertently have to explain the selectable independent deposition rate at a time dependent parameters and also use more different. This developed in [6] of Trukenmüller method for inducing 
apparent equivalence is well thought out and well planned, but it serves no purpose. In conclusion, one can regard it as proven that there is no equivalence between the reference solutions. it should be to recognize a similarity between the calculated concentration profiles, too, what is not the case.

\section{Root Cause Analysis}

It can be regarded as undisputed that the derivations of reference solutions for AUSTAL are faulty.

\section{Root cause analysis in case of deposition and sedimentation}

Incorrect boundary conditions for [15] Axenfeld, Janicke et al and

Applicable boundary conditions [25] VDI KRdL

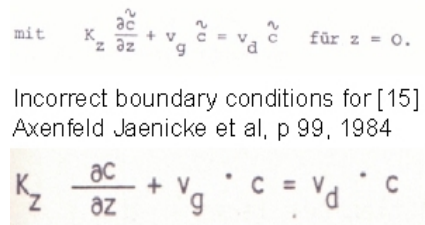

Faulty identical boundary condition for [25] VDI KRdL, p. 257, 1988

\section{for [19] Berlj and and GI.(10)}

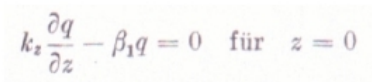

Applicable boundary conditions for [19] Berljand, S. 25, 1982

$k \cdot \frac{\partial c}{\partial z}-v_{d} \cdot c_{0}=0$ für $z=0$

Applicable boundary conditions in Eq. (10) Schenk, 2015
In the theory of momentum, heat and mass transfer can not be traced when the valid boundary condition was used according BERLJAND first

Picture 9. Cause Analysis

Your application for the description of sedimentation and deposition leads to a number of inconsistencies, which have been described by means of suitable formula sets example in Figures 1 to 8 . FIG. The evidence is incorruptible. It must be informed of interest with which the erroneous derivation of the reference solution and the futility of all described tests for homogeneity and other comparative calculations of the authors of AUSTAL be explained. In this context it is not irrelevant to determine that was already being used in [15] in 1984 in the "development of a model for calculating the dust precipitation" with an incorrect boundary condition according image 9. One understands there the deposition rate as the "speed with which an upstanding on the ground column containing the deposition capable material by deposition idles." This unconventional idea on the physics of deposition is obviously recognized as a new school of thought and in [25], VDI 1988 "urban climate and air pollution control, a scientific guide for practice in environmental planning" adopted as universally valid. However, the authors of AUSTAL denied that their own definition contradicts all foundations of the theory of momentum, heat and mass transfer. The correct boundary condition for knowing as repeatedly stated in [19] only for completeness. One can no longer trace back when, this formulation was used in process engineering for the first time and included in the teaching. It is the same with the description of the sinking or sedimentation. Thus, for example, according to equation (01) this provided for the entire scope of all balances as a constant, but you do not know that this must be zero because of the no-slip condition at the lower boundary of the scope of all balances. Due to lack of conceptual model has great difficulty to interpret the results without error here. All other conceptions of authors, for example homogeneity and $3 \mathrm{D}$ wind fields are equally absurd to judge. The list of inconsistencies can be continued as desired. That developed in [15] faulty dispersion model has been further developed later to the particle model LASAT, [15] IB Janicke, and later to AUSTAL. This fatal mistake to Figure 9, the life story of AUSTAL2000 begins.

\section{Able Criticism Terminology}

Subject to the investigations were alone analytical and numerical considerations for solving ordinary differential equations. There is a seminar task instance from the course "Fundamentals of momentum, heat and mass transfer" an academic engineering education with medium difficulty. By analytical solutions are functions continuously described precisely, program developers must prove that their algorithms emulate the analytical solution at a fixed margin of error. However, this presupposes stability, what is nothing to learn in AUSTAL. Instead, we read that solutions may not converge. Criticism of the BERLJAND profile is established, which can be tracked with a study of original literature for [19]. One can learn how deposition processes are physically and mathematically described there. The criticism of the homogeneity test should be faulty. Homogenizing belongs as well as the crushing of the basic operations of process engineering. When homogenizing and crushing the material compensation is effected by an energy input, while in the case of diffusion potential gradient is responsible. When homogenizing you noticed strange vibrations continue at the range limits, which are not further explained. Why the lateral edges must is made periodically? One reason there is this also not. Also edge effects to cause a deviation from the homogeneous turbulence. How this should be done, is questionable. It describes one in [8] S. 53 that bills homogeneous turbulence and spatially variable increment cannot be performed. "The program always chooses homogeneous turbulence a constant time step". Another time, are still carried out according to [9], p.28, Figure 2, invoices in just such homogeneous turbulence and spatially variable increment. House walls are perpendicular to the road and not somehow. Thus, the Euler coordinates are for example particularly suitable for the implementation of flow and dispersion calculations in built-up areas. Unlike AUSTAL "see" dust particles Euler coordinate house walls and do not want to pass. With mass/time, mass/(time* Länge ${ }^{2}$ ), mass/(time* Länge ${ }^{3}$ ) and "volume source over the entire calculation area" are added at four different source term definitions. At the same time you develop the analytical reference equation for a homogeneous differential equation without source term. How did so perform comparative calculations, cannot be traced. The name can be seen already that trajectory models are particularly suitable for modelling long-distance transport, such as in [22 to 23] Eliassen et al. 
has been described. The transport distances rarely amounts generally below $100 \mathrm{~km}$, but more often it. Finally is the dispersion of pollutants along trajectories across continents away also described in [24] Graedel /Crutzen. While qualified prognostic propagation models are the subject of dissertations with scientific advice generally, it has broken in the case AUSTAL another way. According to [10] in 2000 and 2001, the "evaluation system for plant-related immission" presented before a large number of experts invited to three workshops. As you can read there, the workshop had to follow one another closely. "Therefore, there is no time for research." However, contracting and auditoriums need to be able to rely on expertise and scientific thoroughness and Redlich and truthfulness.

\section{Conclusions}

For all case studies to sedimentation and deposition as well as for all homogeneity tests all computing and model parameters are published in full by the authors of AUSTAL. After all practices of scientific work is directed so that the readers are prompted to confirm the results and conclusions through its own considerations and recalculations announced.
This circumstance is not to be understood that one should trust without it because of the high priority of the project and the principal authority. The authors of AUSTAL have a right to know whether you could confirm the correctness of their ideas or not. In the described cases, validate the confirmation of the proof in [2] remains to be faulty. This assertion turns into its opposite. Misunderstandings do not exist. Right and wrong do not allow misunderstandings. Basic knowledge of the theory of momentum, heat and mass transfer is little used. The objections to AUSTAL have hardens. The verification could not have taken place. Even the authors of AUSTAL could not to have been able. The call made in [2] that safety-relevant statements, which have been determined with AUSTAL, have to be checked was not invalidated by [5]. This finding also applies to all other propagation models, which have been validated with the presently described erroneous reference solution to sedimentation and deposition, as well as with the indicated homogeneity tests or use its computing cores. The life story of AUSTAL 2000 begins in 1984 with a fatal error and via LASAT to AUSTAL. She has found in 2016 a temporary end with an unprecedented sleight of hand.

\section{Formula Directory}

area
concentration
concentration in the lowest layer
Enforced source term
Height Control Room
diffusion coefficient
conduction and
convection below
conduction top
convection above
mass flows
function
function
source Term
Equally distributed volume emission
function
heat flow

\begin{tabular}{|c|c|c|}
\hline$m^{2}$ & $\mathrm{t}$ & Time coordinate, incremen \\
\hline$\mu g / m^{3}$ & $\mathrm{~T}, \mathrm{Ti}$ & difference operator \\
\hline$\mu g / m^{3}$ & $\mathrm{~T}$ & Temperature, soil depth \\
\hline$\mu g /\left(m^{2} \cdot s\right)$ & $v_{s}$ & sedimentation \\
\hline $\mathrm{m}$ & $v_{i}$ & deposition rate \\
\hline$m^{2} / s$ & $U, V, W$ & velocity components \\
\hline$\mu g /\left(m^{2} \cdot s\right)$ & $\vee$ & volume \\
\hline$\mu g /\left(m^{2} \cdot s\right)$ & $v_{x}, v_{y}, v_{z}, v_{i}$ & velocity components \\
\hline$\mu g /\left(m^{2} \cdot s\right)$ & $x_{1} y, z, x_{i}$ & coordinates \\
\hline$\mu g /\left(m^{2} \cdot s\right)$ & $\beta$ & deposition rate \\
\hline $\mathrm{Kg} /\left(\mathrm{m}^{2 *} \mathrm{~s}\right)$ & $\eta$ & toughness \\
\hline & $\lambda$ & Thermal conductivity \\
\hline & $\lambda_{a s}, \lambda_{o s}, \lambda_{a s}$ & coefficients \\
\hline$\mu g /\left(m^{2} \cdot s\right)$ & $\lambda_{\text {ass }}, \lambda_{\text {ory }}, \lambda_{\text {art }}$ & coefficients \\
\hline$\mu g /\left(m^{3 *} s\right)$ & $\tau$ & Time increment \\
\hline & $\tau_{\text {ik }}$ & tension \\
\hline $\mathrm{W} / \mathrm{m}^{2}$ & $\Phi$ & deposition \\
\hline
\end{tabular}
$\mathrm{K}, \mathrm{m}$ $\mathrm{m} / \mathrm{s}$ $\mathrm{m} / \mathrm{s}$ $\mathrm{m} / \mathrm{s}$ $\mathrm{m} / \mathrm{s}$ $m^{3}$ $\mathrm{m} / \mathrm{s}$ $m$ $\mathrm{m} / \mathrm{s}$ $\mathrm{kg} /\left(\mathrm{m}^{*} \mathrm{~s}\right)$ $\mathrm{W} /\left(\mathrm{m}^{*} \mathrm{~K}\right)$ $\mathrm{m} / \mathrm{s}$ $\mathrm{m}^{2} / \mathrm{s}$ $s$ $\mathrm{Pa} /\left(m^{2} \cdot s\right)$ 


\section{REFERENCES}

[1] Schenk R.: AUSTAL2000-Methode ist fragwürdig validiert, Stein \& Kies, Ausgabe 132/September-Oktober 2014, S. 8 bis 9

[2] Schenk R.: AUSTAL2000 ist nicht validiert, Immissionssch utz 01.15 , S. 10 bis 21

[3] Schenk R., Markert, B., Fränzle, St.: The Pollutant Spreading Model AUSTAL2000 IS NOT VALIDATED, 7th International Workshop on Biomonitoring of Atmospheric Pollution (BIOMAP7), June 14-19 2015, Lisbon, Portugal

[4] Schenk R.: Replik auf den Beitrag „Erwiderung der Kritik von Schenk anAUSTAL2000 in Immissionsschutz 01/2025“, Immissionsschutz 04.15, S. 189 bis 191

[5] Trukenmüller A. et 13 alii: Erwiderung der Kritik von Schenk anAUSTAL2000 in Immissionsschutz 01/2015, Immissionsschutz 03/2015, S. 114 bis 126

[6] Trukenmüller, A.: Äquivalenz der Referenzlösungen von Schenk und Janicke, Abhandlung Umweltbundesamt Dessau-Roßlau, 2016-03-04

[7] Janicke L.; Klug W.; Rafailides S.; Schatzmann M.; Strimaidis D.;Yamartino R.: Validierung des „Kinematic Simulation Particle Model (KSP-Modell“ für Anwendungen im Vollzug des BImSchG, Bericht 98-295 43354 des Bundesministerium für Umwelt, Naturschutz undReaktorsic herheit, Hamburg 2000

[8] Janicke: AUSTAL 2000, Programmbeschreibung, Dunum, 2002

[9] Janicke L.: IBJparticle, Eine Implementierung des Ausbreitungsmodells, Bericht IBB Janicke

[10] Janicke U., Janicke L.: Entwicklung eines Modellgestützten Beurteilungssystems für den Anlagenbezogenen Immissions schutz, IBJanicke, 2002

[11] VDI: Umweltmeteorologie, Atmosphärische Dispersionsmo delle. Partikelmodell, VDI 3945, Blatt 3

[12] Heimann D.: Ausbreitung von Spurenstoffenbei
Schwachwindlagen, DLR Oberpfaffenhofen, 2001

[13] Röckle R.: Gebäudeumströmung. IMA Freiburg, 2001

[14] Thielen H.; Martens R.: Beiträge der GRS im Rahmen der AUSTAL Workshops, Auftr. Nr. 400003 (AG 1983).

[15] Axenfeld F., Janicke, L., Münch J.: Entwicklung eines Modells zur Berechnung des Staubniederschlages, Umweltforschungsplan des Bundesministers des Innern Luftreinhaltung, Forschungsbericht 10402 562, Dornier System GmbH Friedrichshafen, Im Auftrag des Umweltbundesamtes, 1984

[16] IB Janicke: Ausbreitungsmodell LASAT, Referenzbuch zu Version 2.10, Dezember 2001

[17] Web, Janicke U: AUSTAL2000,http://www.austal2000.de/d e/history.html, http://www.janicke.de/de/products.html

[18] TA Luft: Erste Allgemeine Verwaltungsvorschrift zum Bundesimmissionsschutzgesetz, GMBI, 2002

[19] Berljand M. E.: Moderne Probleme der atmosphärischen Diffusion undVerschmutzung der Atmosphäre, Akademie-Verlag Berlin, 1982

[20] IB Janicke: AUSTAL2000 Geruchsausbreitung im Auftrag von derLandesanstalt für Umweltschutz Karlsruhe, des Niedersächsischen Landesamtes für Ökologie Hildesheim und des Landesamtes NRW Essen, 2011

[21] Schenk R.: AUSTAL2000 ist nicht validiert, neue Entwicklungen bei der Messung und Beurteilung der Luftqualität, VDI Berichte 2250; S. 237 bis242

[22] Eliassen A., Hov O., Isaksen Ivar S. A., Saltbones J., Stordal, F.: A. Lagrangian Long-Range Transport Model with Atmospheric Boundary Layer Chemistry, Journal of Applied Meteorology,Vol. 21 No. 11, Nov. 1982

[23] Eliassen A., Jensen O., Saltbones J.: Das Trajektorienmodell des NILU Institutes und ausgewählte Modellvergleiche, Norwegian Institute for Air Research, Lillestrom, Oktober 1976

[24] Graedel T. E.; Crutzen P. J.: Chemie der Atmosphäre, Spektrum Verlag, Heidelberg, Berlin Oxford, 1994

[25] VDI Kommission Reinhaltung der Luft: Stadtklima und Luftreinhaltung, Springer Verlag, 1988 